\title{
Could vaping help lower smoking rates in Australia?
}

\section{Running head}

The population effect of vaping nicotine

\author{
Authors \\ Colin Mendelsohn ${ }^{1}$, Wayne Hall ${ }^{2}$, Ron Borland ${ }^{3}$ \\ ${ }^{1}$ School of Public Health and Community Medicine, UNSW Sydney, Sydney, Australia \\ ${ }^{2}$ Centre for Youth Substance Abuse Research, University of Queensland, Brisbane, Australia \\ ${ }^{3}$ School of Psychological Sciences, The University of Melbourne, Melbourne, Australia
}

Colin Mendelsohn MB BS (Hons), Conjoint Associate Professor and Tobacco Treatment Specialist, Wayne Hall PhD, Professor, Ron Borland PhD, Professor of Health Psychology - Health Behaviour.

Correspondence to: Dr. Colin Mendelsohn,11 Carlotta Road, Double Bay, NSW 2028, Australia. Tel: 0415976 783; Email: c.mendelsohn@unsw.edu.au

This is the author manuscript accepted for publication and has undergone full peer review but has not been through the copyediting, typesetting, pagination and proofreading process, which may lead to differences between this version and the Version of Record. Please cite this article as doi: 10.1111/dar.13039

This article is protected by copyright. All rights reserved. 


\begin{abstract}
In this brief article, we review the evidence on whether easier access to vaping could help lower smoking rates in Australia. To make a convincing case for vaping the following conditions need to be met: that vaping assists in smoking cessation; that the prevalence of vaping is high enough to produce measurable effects at a population level; and that the decline in smoking prevalence is slower in countries where vaping is less common. The evidence suggests that these criteria are satisfied.
\end{abstract}

Keywords: Electronic cigarettes, Smoking, Addiction, Tobacco harm reduction, Nicotine 
Vaping is widely used globally, either as a smoking cessation aid or an alternative to smoking. However, the sale and use of nicotine for vaping is effectively banned in Australia. In this brief article, we review the evidence on whether easier access to vaping could help lower smoking rates in Australia.

To make a convincing case for vaping the following conditions need to be met: that vaping assists in smoking cessation; that the prevalence of vaping is high enough to produce measurable effects at a population level; and that the decline in smoking prevalence is slower in countries where vaping is less common. The evidence suggests that these criteria are satisfied.

\section{Can vaping facilitate cessation?}

\section{Randomised controlled trials}

Well-designed randomised controlled trials (RCT) can demonstrate whether interventions are effective by randomising patients to treatment or a control condition. Random assignment makes it more likely that the two groups of patients do not differ in any way that will affect treatment outcomes and allows us to attribute any differences in outcome to the treatment.

Early evidence from a small number of RCTs using vaping devices (e-cigarettes) with low nicotine delivery suggested that vaping was more effective that placebo vaping, but not more effective than other forms of nicotine replacement therapy [1]. This may have been because of a lack of studies or the relative ineffectiveness of the early vaping devices. Two recent high-quality, pragmatic trials have now shown that vaping can be more effective than conventional nicotine replacement therapy (NRT).

In one trial of 886 smokers by Hajek et al., run within the National Health Service stop-smoking service, those randomised to vaping with a modern device and quitting support were nearly twice as likely to quit as smokers who were given NRT [2]. Both groups were offered behavioural support. Biochemically validated abstinence rates at 12 months were $18 \%$ for the vaping group and $9.9 \%$ for NRT users (RR 1.83). Ninety percent of subjects in the NRT arm used a combination of products, typically a nicotine patch and a nicotine gum or lozenge, which is currently established as the most effective cessation pharmacotherapy [3]. The effect from vaping appears to be at least in part due to sustained use, with $80 \%$ of those who quit in the vaping arm still using their vaping device after 12 months (compared with $9 \%$ in the NRT arm).

The second trial by Walker et al. in New Zealand randomised 1124 smokers to nicotine patch-only $(n=125)$, nicotine patch plus nicotine vaping $(n=500)$ and nicotine patch plus nicotine-free vaping $(n=499)$. All subjects were offered behavioural support [4]. Those randomised to combined patch and nicotine vaping had triple the biochemically validated continuous abstinence rates of the patchonly group at 6 months (7\% vs 2\%). The quit rate for the patch and nicotine-free vaping group was $4 \%$. However, only around $40 \%$ of this community-based sample provided a biochemical sample, meaning this is a very conservative estimate of effect size. A more realistic estimate used by the authors, which extrapolated adjustment for biochemical verification gave success rates of $17 \%$ versus $10 \%$, showing a larger benefit for the active nicotine vaping condition. 
Neither study found any evidence of higher rates of treatment-related adverse effects in the vaping groups.

Together these studies show that nicotine vaping improves cessation over NRT when used alone [2] or with patches [4]. The magnitude of the benefit is that between 7 and 8 extra quitters will result per 100 who use vaping to try to quit.

\section{Other evidence of likely effectiveness}

Observational studies such as cohort studies can help assess whether the effects found in RCTs are observed in the real world. Care is needed to control for potential biases such as including users who are not trying to quit, not differentiating between occasional or regular vaping, recruiting smokers who have already failed to quit smoking at baseline and failing to control for other confounders.

Unfortunately, many published studies are too flawed in one of these ways to provide unbiased information on the effectiveness of vaping for quitting. However, comprehensive analyses of the more robust observational studies by Glasser et al. and Villanti et al. found that vaping facilitates quit attempts and increases cessation $[5,6]$.

Population studies in the US and the UK have found also that smokers who use vaping to quit have significantly higher quit rates than those who do not [7-10]. Quit attempts and quit rates have been increasing since vaping became popular.

An English study of 19,000 smokers compared the real-world effectiveness of quitting aids used in the most recent quit attempt in the last 12 months [10]. Those who used vaping devices had significantly higher quit rates than those who bought NRT over-the-counter and those who used no treatment.

A US study of a nationally representative sample of nearly 23,000 smokers also found that those who used a vaping device were $73 \%$ more likely to quit than non-users $(8.2 \%$ v $4.8 \%)$ and were also more likely to make a quit attempt [7]. Similar results were found in a study of 60,000 25-45-yearolds in the US: smokers who were vaping were $65 \%$ more likely to have quit smoking in the last 12 months than smokers who were not [8].

Daily vaping is more effective than less frequent use. In large studies in the US, daily vapers were 3-8 times more likely to quit than smokers who did not vape $[11,12]$.

Other studies have shown that modern devices are more effective for cessation than earlier 'cigalike' models [11, 13] although not all studies have found clear effects [14].

Overall the observational evidence indicates that daily vaping with higher nicotine delivery models can increase quit rates.

Is there enough vaping to influence population smoking rates? 
The population health impact of vaping is determined by its uptake as well as its effectiveness. In countries where smokers can readily access them, vaping devices have been used by a large enough proportion of smokers to affect the population prevalence of cigarette smoking. Vaping devices are now the most popular quitting aid in the United Kingdom [15], the United States [16] and the European Union [17].

In England in 2019, vaping devices were used in 31.9\% of quit attempts, followed by NRT over-thecounter (13.7\%), varenicline (4.4\%) and prescribed NRT (4\%) [15]. In France since 2010, 27\% of smokers who tried to quit used vaping compared to $18 \%$ who used NRT [18].

The number of adults vaping continues to grow rapidly and was estimated to be at least 40 million globally in 2018 by market research group Euromonitor [19]. Current adult vaping rates range from $2-6 \%$ of the adult population in countries where vaping is legal and readily available.

\section{[FIGURE 1]}

\section{Decline in smoking rates}

It is not possible to conclusively prove that changes in population smoking can be attributed to any one intervention. Nonetheless, it is noteworthy that the decline in smoking in both the US and England has accelerated over the period that vaping has become widespread and population quit rates have increased $[7,30]$. These changes do not appear to be explained by other factors such as tax rises and public health marketing campaigns [7].

Given that vaping is widely used and can be effective, it is more likely than not to be contributing to this rapid decline in smoking. We can also be confident that increased vaping it is not significantly inhibiting progress towards a smoke-free society.

\section{[FIGURE 2]}

By contrast, Australia has a low current vaping rate of $1.2 \%$ [20] and the decline in smoking prevalence appears to have slowed since 2013 according to two national surveys [20, 35]. This is despite Australia having amongst the highest priced cigarettes in the world, the introduction of plain packaging and very rigorous tobacco control laws. The comparison between countries increases the likelihood that the differences observed are at least in part due to a positive effect of vaping on reducing smoking prevalence.

\section{Conclusion}

Vaping appears to be lowering smoking rates in countries that allow its use. Vaping nicotine increases success rates for smoking cessation as demonstrated in RCTs and confirmed in populationbased studies. The population impact of vaping is amplified because of its popularity with smokers. Vaping has had a wide uptake in communities where it is allowed and has reached more smokers than quitting aids such as NRT. 
There is evidence that vaping has increased quit attempts and reduced national smoking rates in the UK and US, where the decline in prevalence of smoking has accelerated. This contrasts with countries such as Australia with restrictive vaping policies where such declines in prevalence are not being observed.

Taken together this evidence provides compelling support for the proposition that vaping is an effective smoking cessation aid that is contributing to a lower smoking prevalence in countries where its use is not actively discouraged.

These positive effects have largely been achieved without official government support or endorsement in most countries. A greater impact would be expected if public health officials encouraged smokers to try vaping where conventional cessation strategies have failed.

Vaping has the potential to help rejuvenate smoking cessation in Australia and improve public health if smokers are allowed easier and legal access to appropriately regulated products. This can and should be done in ways that minimise uptake by non-smokers and young people e.g. by limiting sales to licensed vaping shops, pharmacies and adult stores, and restricting advertising to adult smokers such as at the point of sale.

\section{Conflicts of Interest}

No funding was provided for the preparation of this manuscript

Colin Mendelsohn received funding from Pfizer Australia, Johnson \& Johnson Pacific and Perrigo Australia for teaching, consulting and conference expenses. Colin Mendelsohn has never received payments from electronic cigarette or tobacco companies. He is a Board member of the Australian Tobacco Harm Reduction Association, a health promotion charity which has received unconditional funding for establishment costs from small Australian vape businesses. Vape industry funding has not been accepted since March 2019.

Wayne Hall and Ron Borland have no conflicts of interest to declare. 


\section{References}

1. Hartmann-Boyce J, McRobbie H, Bullen C, Begh R, Stead LF, Hajek P. Electronic cigarettes for smoking cessation. Cochrane Database Syst Rev 2016;9:CD010216.

2. Hajek P, Phillips-Waller A, Pfzulki D, Pescola F, Myers Smith K, Bisal N, et al. A randomised trial of e-cigarettes versus nicotine replacement therapy. N Engl J Med 2019;380:629-37.

3. Cahill K, Stevens S, Perera R, Lancaster T. Pharmacological interventions for smoking cessation: an overview and network meta-analysis. Cochrane Database Syst Rev 2013;5:CD009329.

4. Walker N, Parag V, Verbiest M, Laking G, Laugesen M, Bullen C. Nicotine patches used in combination with e-cigarettes (with and without nicotine) for smoking cessation: a pragmatic, randomised trial. Lancet Respir Med 2020;8:54-64.

5. Glasser AM, Collins L, Pearson JL, Abudayyeh H, Niaura RS, Abrams DB, et al. Overview of Electronic Nicotine Delivery Systems: A Systematic Review. Am J Prev Med 2017;52:e33-e66.

6. Villanti AC, Feirman SP, Niaura RS, Pearson JL, Glasser AM, Collins LK, et al. How do we determine the impact of e-cigarettes on cigarette smoking cessation or reduction? Review and recommendations for answering the research question with scientific rigor. Addiction 2017;113:391404.

7. Zhu SH, Zhuang YL, Wong S, Cummins SE, Tedeschi GJ. E-cigarette use and associated changes in population smoking cessation: evidence from US current population surveys. BMJ 2017;358:j3262.

8. Johnson L, Ma Y, Fisher SL, Ramsey AT, Chen LS, Hartz SM, et al. E-cigarette usage is associated with increased past-12-month quit attempts and successful smoking cessation in two US population-based surveys. Nicotine Tob Res 2019;21:1331-8.

9. Beard E, West R, Michie S, Brown J. Association between electronic cigarette use and changes in quit attempts, success of quit attempts, use of smoking cessation pharmacotherapy, and use of stop smoking services in England: time series analysis of population trends. BMJ 2016;354:i4645.

10. Jackson S, Kotz D, West R, Brown J. Moderators of real-world effectiveness of smoking cessation aids: a population study. Addiction 2019;114:1627-38.

11. Berry KM, Reynolds LM, Collins JM, Siegel MB, Fetterman JL, Hamburg NM, et al. E-cigarette initiation and associated changes in smoking cessation and reduction: the Population Assessment of Tobacco and Health Study, 2013-2015. Tob Control 2018;28):42-9.

12. Giovenco DP, Delnevo CD. Prevalence of population smoking cessation by electronic cigarette use status in a national sample of recent smokers. Addict Behav 2017;76:129-34.

13. Hitchman SC, Brose LS, Brown J, Robson D, McNeill A. Associations between e-cigarette type, frequency of use, and quitting smoking: Findings From a longitudinal online panel survey in Great Britain. Nicotine Tob Res 2015;17:1187-94.

14. Weaver SR, Huang J, Pechacek TF, Heath JW, Ashley DL, Eriksen MP. Are electronic nicotine delivery systems helping cigarette smokers quit? Evidence from a prospective cohort study of U.S. adult smokers, 2015-2016. PLoS One. 2018;13:e0198047.

15. West R, Brown J. Smoking Toolkit Study. Smoking in England 2019. Available at: www.smokinginengland.info/latest-statistics/ (accessed September 2019).

16. Caraballo RS, Shafer PR, Patel D, Davis KC, McAfee TA. Quit methods used by US Adult cigarette smokers, 2014-2016. Prev Chronic Dis 2017;14:E32.

17. Directorate-General for Health and Food Safety. Attitudes of Europeans towards tobacco and electronic cigarettes, Special Eurobarometer 458 2017. Available at:

https://data.europa.eu/euodp/en/data/dataset/S2146 871458 ENG (accessed September 2019).

This article is protected by copyright. All rights reserved. 
18. Gomajee R, El-Khoury F, Goldberg M, Zins M, Lemogne C, Wiernik E, et al. Association Between Electronic Cigarette Use and Smoking Reduction in France. JAMA Intern Med 2019 [Epub ahead of print].

19. BBC News. Vaping - the rise in five charts 2018. Available at:

https://www.bbc.com/news/business-44295336 (accessed September 2019).

20. Australian Institute of Health and Welfare. National Drug Strategy Household Survey (NDSHS) 2016: detailed findings. Drug Statistics series no. 31. Cat. no. PHE 214. Canberra: AlHW. 2017 Available at: https://www.aihw.gov.au/getmedia/15db8c15-7062-4cde-bfa4-

3c2079f30af3/21028.pdf.aspx?inline=true (accessed September 2019).

21. Kotz D, Bockmann M, Kastaun S. The Use of Tobacco, E-Cigarettes, and Methods to Quit Smoking in Germany. Dtsch Arztebl Int 2018;115:235-42.

22. Hedman L, Backman H, Stridsman C, Bosson JA, Lundback M, Lindberg A, et al. Association of Electronic Cigarette Use With Smoking Habits, Demographic Factors, and Respiratory Symptoms. JAMA Netw Open 2018;1:e180789.

23. Ruokolainen $\mathrm{O}$, Ollila $\mathrm{H}$, Karjalainen $\mathrm{K}$. Determinants of electronic cigarette use among Finnish adults: Results from a population-based survey. Nordic Studies on Alcohol and Drugs 2017;34:471-80.

24. European Commission. Special Eurobarometer 458. Attitudes of Europeans towards tobacco and electronic cigarettes 2017. Available at:

https://data.europa.eu/euodp/en/data/dataset/S2146_87_1_458_ENG (accessed September 2019). 25. Health Canada. Canadian Tobacco, Alcohol and Drugs Survey (CTADS): summary of results for 2017. 2018.Available at: https://www.canada.ca/en/health-canada/services/canadian-tobaccoalcohol-drugs-survey/2017-summary.html\#n2 (accessed July 2019).

26. Dai H, Leventhal AM. Prevalence of e-Cigarette use among adults in the united states, 20142018. JAMA 2019 [Epub ahead of print].

27. Pasquereau A, Guignard R, Andler R, Nguyen-Thanh V. Electronic cigarettes, quit attempts and smoking cessation: a 6-month follow-up. Addiction 2017;112:1620-8.

28. Health Promotion Agency New Zealand. Health and Lifestyles Survey. 2018.Available at: https://kupe.hpa.org.nz/hls-2018 (accessed October 2018).

29. Farsalinos KE, Siakas G, Poulas K, Voudris V, Merakou K, Barbouni A. Electronic cigarette use in Greece: an analysis of a representative population sample in Attica prefecture. Harm Reduct J. 2018;15:20.

30. Office for National Statistics. Adult smoking habits in the UK: 2018. 2019 Available at: https://www.ons.gov.uk/releases/adultsmokinghabitsintheuk2018 (accessed July 2019).

31. Australian Institute of Health and Welfare. National Drug Strategy Household Surveys 20102018. Available at: https://www.aihw.gov.au/about-our-data/our-data-collections/national-drugstrategy-household-survey. (accessed July 2019)

32. Australian Bureau of Statistics. National Health Surveys 2011/2012-2017/2018. Available at: https://search.abs.gov.au/s/search.html?query=national+health+survey\&collection=abs\&form=simp le\&profile=_defaul. (accessed July 2019)

33. Office for National Statistics. Adult smoking habits in the UK: 2018. Available at:

https://www.ons.gov.uk/peoplepopulationandcommunity/healthandsocialcare/healthandlifeexpect ancies/bulletins/adultsmokinghabitsingreatbritain/2018\#the-proportion-who-are-current-smokersin-the-uk-its-constituent-countries-and-local-areas-2011-to-2018. (accessed July 2019)

34. National Centre for Health Statistics, National Health Interview Survey. U.S. Department of Health and Human Services, Centers for Disease Control and Prevention. Prevalence of current cigarette smoking among adults aged 18 and over: United States, 2006-2018. Available at:

This article is protected by copyright. All rights reserved. 
https://public.tableau.com/profile/tina.norris\#!/vizhome/FIGURE8_1/Dashboard8_1. (accessed July 2019)

35. Australian Bureau of Statistics. National Health Survey: First Results, 2017-18. Catalogue no 4364 0.55.001. 2018.Available at:

http://www.abs.gov.au/ausstats/abs@.nsf/Lookup/by\%20Subject/4364.0.55.001 2017-

18 Main\%20Features Smoking 85 (accessed July 2019).

This article is protected by copyright. All rights reserved. 
Figure 1

Adult vaping prevalence in selected western countries

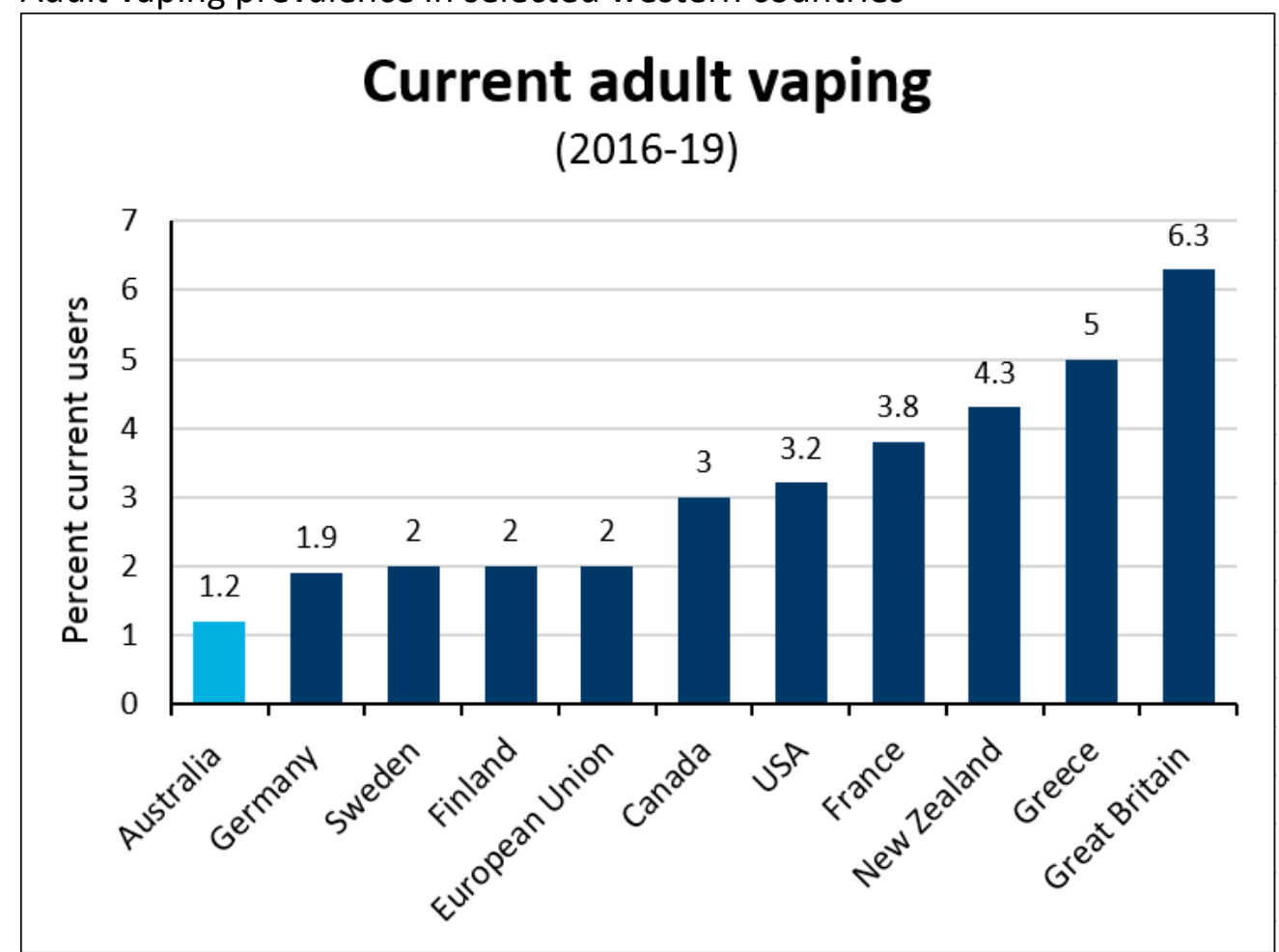

Australia [20], Germany [21], Sweden [22], Finland [23], European Union [24], Canada [25], United States [26], France [27], New Zealand [28], Greece [29], Great Britain [30] 
Figure 2

Adult cigarette smoking prevalence in England, US and Australia

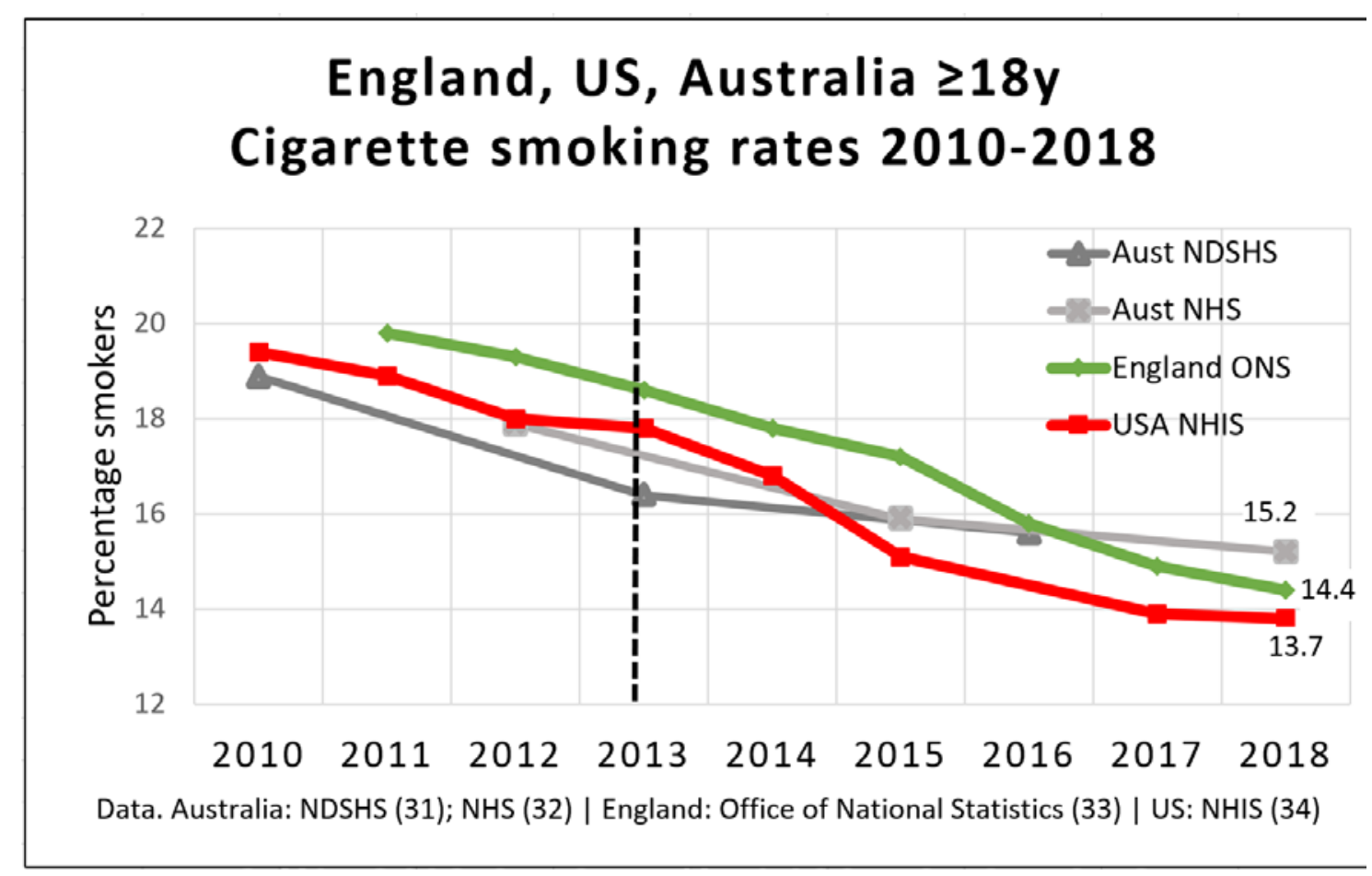

NDSHS, National Drug Strategy Household Survey; NHIS, National Health Interview Survey; NHS, National Health Service. 
Figure 1

Adult vaping prevalence in selected western countries

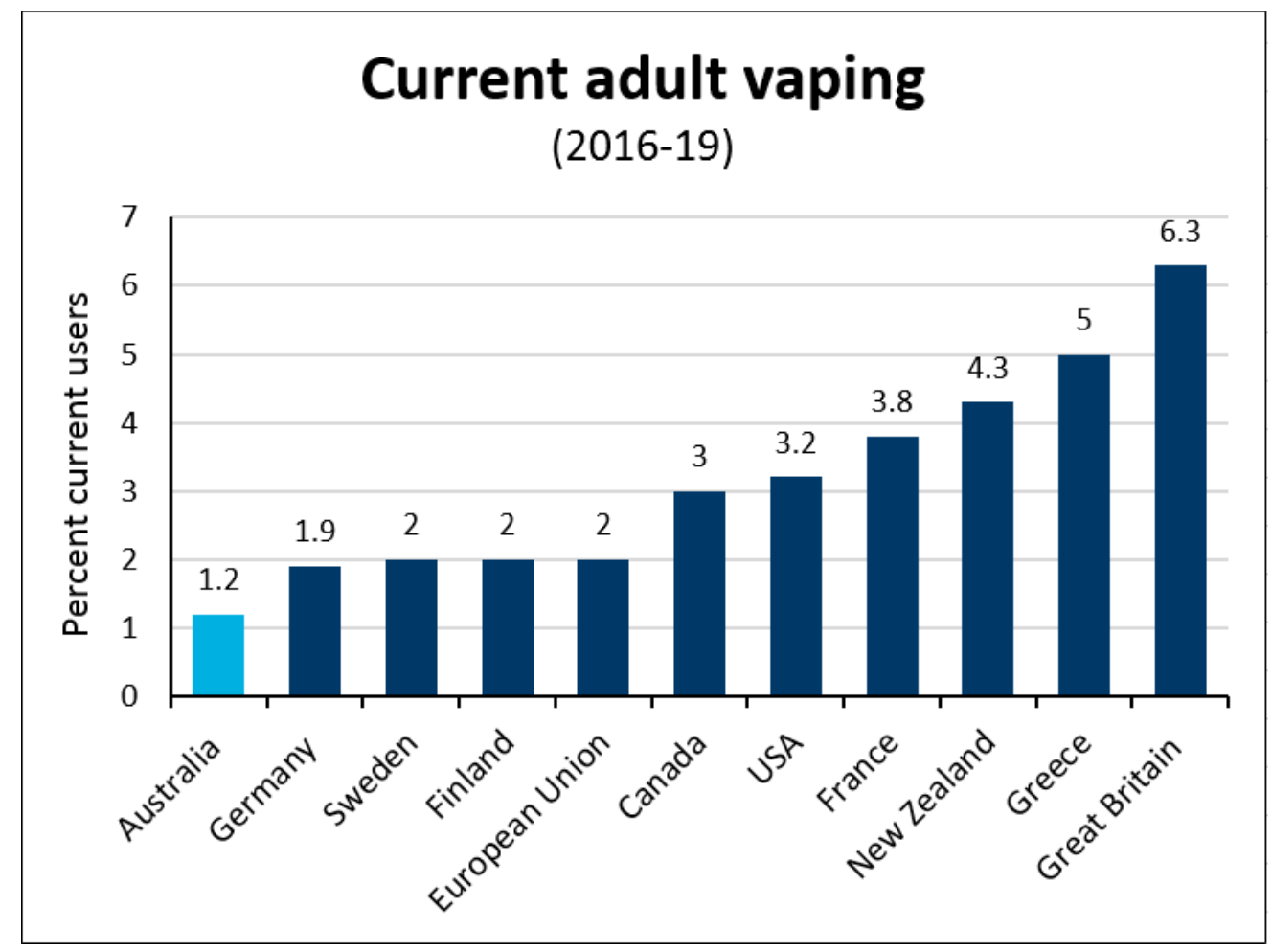

Australia [20], Germany [21], Sweden [22], Finland [23], European Union [24], Canada [25], United States [26], France [27], New Zealand [28], Greece [29], Great Britain [30] 


\section{Figure 2}

Adult cigarette smoking prevalence in England, US and Australia

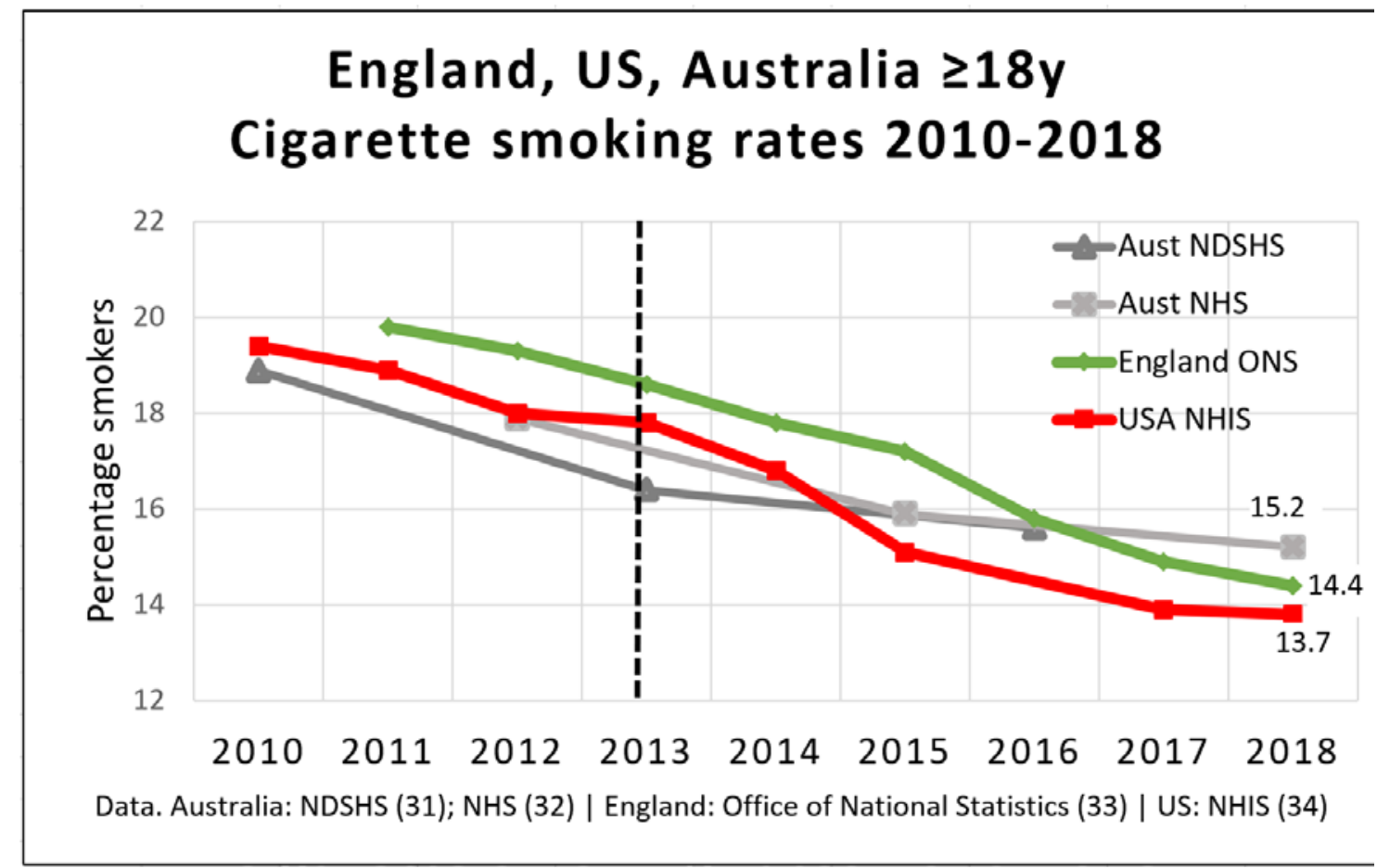

NDSHS, National Drug Strategy Household Survey; NHIS, National Health Interview Survey; NHS, National Health Service. 


\section{University Library}

\section{- M M I N E R VA A gateway to Melbourne's research publications}

Minerva Access is the Institutional Repository of The University of Melbourne

Author/s:

Mendelsohn, C;Hall, W;Borland, R

Title:

Could vaping help lower smoking rates in Australia?

Date:

2020-01-27

Citation:

Mendelsohn, C., Hall, W. \& Borland, R. (2020). Could vaping help lower smoking rates in Australia?. DRUG AND ALCOHOL REVIEW, 39 (4), pp.415-418. https://doi.org/10.1111/ dar.13039.

Persistent Link:

http://hdl.handle.net/11343/275297 